\title{
Territorialidade e racismo ambiental: elementos para se pensar a educação ambiental crítica em unidades de conservação
}

Lara Moutinho-da-Costa ${ }^{1}$

Resumo: Em 2005, o I Seminário Brasileiro contra o Racismo Ambiental, organizado pelo projeto Brasil Sustentável e Democrático (BSD) e o Laboratório de Estudos, Pesquisas e Ação sobre Cidadania, Territorialidade e Ambiente da Universidade Federal Fluminense (LACTA/UFF), trouxe para a sociedade a discussão sobre racismo ambiental no Brasil evidenciando, pela primeira vez no país, casos de racismo ambiental na conservação da natureza. O presente estudo busca esclarecer o que é racismo ambiental e como ele se articula com territorialidade e conservação da natureza, dando contribuições para a educação ambiental crítica desenvolvida em áreas protegidas.

Palavras-chave: Conservação da natureza. Territorialidade. Racismo ambiental.

Abstract: In 2005, the I Brazilian Seminar against Environmental Racism, organized by the Sustainable and Democratic Brazil Project (BSD) and the Laboratory of Studies, Research and Action on Citizenship, Territoriality and Environment of the Fluminense Federal University (LACTA/UFF), brought into society the discussion about environmental racism in Brazil by presenting, for the first time in the country, cases of racism in environmental conservation. This study attempts to clarify what is environmental racism and how it is articulated with territoriality and nature conservation, therefore contributing to enhancing critical environmental education in protected areas.

Keywords: Nature conservation. Territoriality. Environmental racism.

\section{Introdução}

"A crítica arrancou as flores imaginárias das correntes, não para que o homem as suporte sem fantasias ou consolo, mas para que lance fora as correntes e colha a flor viva." (Karl Marx)

1 Professora dos cursos de Pós-Graduação da Academia Brasileira de Arte e Ciência Oriental (ABACO); Superintendente de Educação Ambiental da Secretaria de Estado do Ambiente do Rio de Janeiro laraflower@gmail.com 
Em 2005, o I Seminário Brasileiro contra o Racismo Ambiental, organizado pelo Projeto Brasil Sustentável e Democrático (BSD/FASE²) e o Laboratório de Estudos, Pesquisas e Ação sobre Cidadania, Territorialidade e Ambiente da Universidade Federal Fluminense (LACTA/UFF) ${ }^{3}$, trouxe para a sociedade a discussão sobre racismo ambiental no país. $O$ seminário evidenciou, entre outros, casos de racismo ambiental na conservação da natureza, apresentando depoimentos e denúncias contra o órgão gestor das unidades de conservação federais, na época o IBAMA, envolvendo unidades de conservação tanto rurais quanto urbanas, como o caso dos quilombolas do rio Trombetas (PA), atingidos pela presença de mineradora, de Reserva Biológica e de Floresta Nacional em área de uso tradicional, e o caso do Parque Nacional da Tijuca (RJ), que envolve conflitos relacionados ao uso público religioso dos espaços territoriais da unidade por tradições religiosas não hegemônicas, principalmente as de matrizes africanas.

Mas o que é racismo ambiental e como ele se articula com conservação da natureza? Práticas, regras impostas e relações estabelecidas pelo órgão gestor das unidades de conservação (UCs) federais, hoje não mais o IBAMA, mas o Instituto Chico Mendes de Biodiversidade (ICMBio), estariam causando impacto sobre etnias em vulnerabilidade que poderiam ser classificadas como práticas de racismo ambiental e, portanto, injustiça ambiental? Dito de outra forma, povos e comunidades consideradas tradicionais ${ }^{4}$, como os quilombolas, pescadores, índios e mesmo os povos de santo e de terreiro, poderiam também ser classificados como grupos sociais vítimas de injustiças ambientalmente racistas causadas pela conservação da natureza, se transformando em povos afetados/atingidos por unidades de conservação, ou "refugiados da conservação", na perspectiva de Dowie (2005)?

Como toda instituição deve ser analisada à luz da sociedade, sistema e contexto histórico/político/econômico nos quais está inserida, para responder à questão levantada e entender como territorialidade e racismo ambiental se inserem no campo da conservação da natureza, faremos um voo pela história para analisar, primeiro, o surgimento do conceito de raça e seu uso ideológico como critério de classificação da população mundial e de controle do trabalho (de seus recursos e produtos) feito pelo Capitalismo, e, em seguida, os impactos gerados pelos processos de expansão de fronteiras do Estado-Nação brasileiro,

${ }^{2}$ FASE - Federação de Órgãos para Assistência Social e Educacional. Foi fundada em 1961. É uma organização não governamental, sem fins lucrativos, que atua em seis estados brasileiros e tem sua sede nacional no Rio de Janeiro. Desde suas origens, esteve comprometida com o trabalho de organização e desenvolvimento local, comunitário e associativo.

3 O LACTA é um grupo de estudos, pesquisas e ação sobre Cidadania, Territorialidade e Ambiente criado em 1995, na Universidade Federal Fluminense, e cadastrado no GRPESq do CNPq (Cadastro dos Grupos de Pesquisas do Conselho Nacional de Pesquisas do Ministério da Ciência e Tecnologia).

${ }^{4}$ Definidas pelo Decreto $\mathrm{n}^{\circ}$ 6.040, de 07 de fevereiro de 2007, que institui a Política Nacional de Desenvolvimento Sustentável dos Povos e Comunidades Tradicionais. 
incluída a instituição de áreas protegidas, sobre os diversos povos e comunidades tradicionais.

Será visto que foi com a descoberta da América que nasceu, ao mesmo tempo, o racismo e o capitalismo mundial, na medida em que, ideologicamente, os colonizadores europeus usaram artifícios filosóficos, religiosos e legais para justificarem a exploração do trabalho não pago de índios e negros e assim acumularem capital. Nesse contexto, a instituição do racismo, em suas diversas modalidades de expressão, foi fundamental para a consagração do que Quijano (2005) chama de "Colonialidade do Poder"5, que para o autor é racista, capitalista e eurocentrada em sua base e continua atuando pelo mundo de maneira globalizada.

\section{Colonialidade do Poder e do Saber e Capitalismo Mundial: Poder, Raça e Classe}

Para o sociólogo Aníbal Quijano, a classificação social da população mundial de acordo com a ideia de raça foi, e ainda é, um dos eixos fundamentais do capitalismo, ou melhor, de um padrão de poder mundial que nasceu com a constituição da América e do que esse autor chama de "capitalismo colonial/moderno e eurocentrado", a ponta de um sistema de poder - SistemaMundo, na perspectiva de Immanuel Wallerstein ${ }^{6}$ - que culmina hoje com o processo conhecido como Globalização. Para esse autor, "a idéia de raça nada mais é do que uma construção mental que expressa a experiência básica da dominação colonial e que desde então permeia as dimensões mais importantes do poder mundial, incluindo a sua racionalidade específica, o eurocentrismo". Implica, consequentemente, um elemento de colonialidade no padrão de poder hoje hegemônico. (QUIJANO, 2005, p. 227-229).

Para isso dois processos históricos convergiram e se associaram, estabelecendo-se como os dois eixos fundamentais do novo padrão de poder: a) a codificação das diferenças entre conquistadores e conquistados na ideia de raça, ou seja, uma estrutura biológica supostamente distinta que situava os conquistados em situação natural de inferioridade em relação aos conquistadores; b) a articulação de todas as formas históricas de controle do trabalho em torno do capital e do mercado, em seu movimento de expansão e universalismo.

Nesse contexto, raça é uma categoria mental da modernidade que, segundo Quijano (1992, 2005), não tem história conhecida antes da América, tendo sido aplicada inicialmente aos "índios", e não aos "negros", identidades sociais que ainda estavam sendo formadas. Com o tempo, os colonizadores codificaram como cor os traços fenotípicos (cor da pele, dos olhos, tipo de cabelo etc.) dos colonizados e a assumiram como característica emblemática da categoria racial.

\footnotetext{
${ }^{5}$ Sobre o conceito de Colonialidade do Poder ver Quijamo (2005).

6 Sobre o conceito de Sistema-mundo ver Hopkins; Wallerstein (1982 apud QUIJANO, 2005, p. 227-278) e Wallerstein (1974-1989).
} 
Desse modo, raça apareceu antes que cor na história da classificação social da população mundial.

Segundo o mesmo autor, a formação de relações sociais fundadas nessa ideia produziu na América identidades sociais historicamente novas, como indios, negros e mestiços (desdobrados em mamelucos, cafuzos, pardos e bugres), redefinindo outras, como espanhol e português e depois europeu, que até então indicavam apenas procedência geográfica, mas desde então adquiriram também uma conotação racial. E, na medida em que as relações sociais que se estabeleciam eram relações de dominação, tais identidades foram também associadas às hierarquias, lugares e papéis sociais correspondentes, ou seja, às novas classes sociais que se constituíam e ao padrão de poder que se impunha. Assim, raça e identidade racial foram estabelecidas como instrumentos de classificação social básica da população e de dominação e legitimação da expropriação, uma maneira de legitimar as relações de dominação impostas pelos colonizadores.

A constituição da Europa como nova identidade depois da América e a expansão do colonialismo europeu pelo resto do mundo conduziram à elaboração da perspectiva eurocêntrica do conhecimento e, com ela, à elaboração da ideia de raça como naturalização dessas relações coloniais de dominação entre europeus e não europeus, agora brancos e não brancos.

Immanuel Wallerstein partilha dessa perspectiva de Quijano e discorre sobre etnização da vida comunitária e da força de trabalho no Capitalismo Histórico, no qual forças de trabalho foram criadas nos lugares certos, com os níveis mais baixos de remuneração (quando não total ausência, como na servidão e na escravidão), no interesse dos que desejavam facilitar a acumulação de capital. Para esse autor, o racismo foi o modo como vários seguimentos da força de trabalho foram obrigados a se relacionar um com o outro no interior de uma mesma estrutura econômica. Nesse sentido, o racismo é a justificativa ideológica da hierarquização da força de trabalho e da distribuição, altamente desigual, da recompensa:

[...] o racismo é o conjunto das afirmações ideológicas combinado com o conjunto de práticas duradouras que resultaram em manter, ao longo do tempo, uma alta correlação entre etnicidade e localização da força de trabalho. (WALLERSTEIN, 2001, p. 6667).

De modo bastante pertinente, Wallerstein define "grupos étnicos" como "grupos dimensionáveis de pessoas para as quais se reserva um certo papel ocupacional/econômico, em relação a outros grupos vivendo na proximidade geográfica".

Também para Martiano J. Silva (1995), escritor baiano que desnudou o "mito da democracia racial" no Brasil, o uso do trabalho não pago de índios (inicialmente escravos, depois servos) e negros (escravos) teve intenção capitalista, pois favoreceu a acumulação de capital. Esse período histórico foi, para Marx (2006), a chamada fase de "acumulação primitiva do capital". 
Assim, o racismo aparece não como um detalhe mais ou menos acidental, mas como um elemento fundamental à constituição e universalização do Capital no Sistema-Mundo Capitalista em que estamos inseridos ainda hoje, que para Quijano (2005) ainda mantém seu caráter colonial. Nas palavras de Albert Memmi (2007, p. 110):

O racismo é a melhor expressão do fato colonial, e um dos traços mais significativos do colonizador, e do colonialista. Não apenas estabelece a discriminação fundamental entre colonizador e colonizado, condição sine qua non da vida colonial, como fundamenta sua imutabilidade.

Ou seja, enquanto a colonialidade existir (expressa através da opressão, dominação, sistema de privilégios etc.), existirá o racismo, que tem sido uma ideologia abrangente para justificar a desigualdade e a discriminação praticada contra grupos sociais minoritários e não hegemônicos. Mais que isso: “Tem servido para que grupos sejam socializados dentro dos papéis que devem ocupar na economia, constituindo-se num dos pilares fundamentais do capitalismo histórico e das sociedades capitalistas" (WALLERSTEIN, 2001, p. 68-69).

\section{A Lógica Instrumental da Colonialidade do Poder: o Eurocentrismo}

$\mathrm{Na}$ perspectiva de Lander (2005), além da Colonialidade do Poder, houve uma Colonialidade do Saber ${ }^{7}$, uma vez que os europeus expropriaram as populações colonizadas e escravizadas de seus mais aptos produtores culturais. Além disso, reprimiram tanto quanto puderam as formas de produção de conhecimento dos colonizados e escravizados, seus padrões de produção de sentidos, seu universo simbólico, sua maneira de ver o mundo e de expressar e objetivar sua subjetividade. E mais: forçaram os colonizados e os escravizados a aprender a cultura dos dominadores em tudo o que fosse útil para a reprodução da dominação, tanto no campo da atividade material e tecnológica como no da subjetiva, especialmente a religiosa, impondo-se para todo o sistema-mundo que surgia a religiosidade judaico-cristã.

Nesse contexto, as experiências, histórias, formas de pensar, sentir e significar o mundo e os recursos e produtos culturais de todo um mundo dominado e colonizado terminaram inseridos numa única ordem cultural global, em torno da hegemonia europeia ocidental. A Europa concentrou, além do poder capitalista, o controle da subjetividade, da cultura, do conhecimento e da produção do conhecimento.

Segundo Wallerstein (2001, p. 68-69), o êxito da Europa Ocidental em transformar-se no centro do moderno Sistema-Mundo desenvolveu nos europeus um traço comum aos dominadores coloniais e imperiais da história, o etnocentrismo, ou seja, a tendência em identificar e classificar os outros povos a

${ }^{7}$ Para aprofundamentos sobre Colonialidade do Saber ver Lander (2005, p. 21-54). 
partir de seu próprio sistema de valores. De acordo com essa perspectiva, a modernidade e a racionalidade, assim como a pretensa civilidade que as acompanha, foram imaginadas como práticas exclusivas dos europeus. Desse ponto de vista, as relações intersubjetivas e culturais entre Europa, ou melhor, Europa Ocidental, e o restante do mundo foram codificadas em novas categorias binárias: primitivo-civilizado, mágico/mítico-científico, irracional-racional, antigonovo, tradicional-moderno, oriente-ocidente. Em resumo, Europa e não Europa.

Foi essa perspectiva de conhecimento, evolucionista, binária e dualista, que se tornou mundialmente hegemônica, acompanhando o fluxo da expansão do domínio colonial da Europa sobre o mundo. E, segundo Quijano (2005), ela foi tão bem-sucedida que globalizou seus dois mitos principais: o primeiro relacionado à ideia-imagem da história da civilização humana como uma trajetória evolucionista que parte de um estado de natureza anterior/primitiva/ irracional/atrasada/mítico-mágica/tradicional e culmina na Europa, posterior/ civilizada/racional/nova/científica/moderna; o segundo, o de outorgar sentido às diferenças entre Europa e não Europa como diferenças raciais, e não relativas às condições materiais de existência e às relações estabelecidas entre um grupo de dominadores e outro de dominados, ou seja, de história e poder. Ambos os mitos podem ser reconhecidos no fundamento do evolucionismo, do tecnicismo cientificista e do dualismo, três dos elementos nucleares do eurocentrismo e de sua lógica instrumental.

Assim, portador dos valores da civilização e da história, o colonizador europeu (branco, capitalista e racista) realiza uma missão: tem o mérito de iluminar as infames trevas dos povos por ele dominados. Está justificada sua dominação. Nas palavras do antropólogo Kapengele Munanga (1984, p. 40), “o etnocentrismo é tão antigo quanto a própria humanidade e sempre teve matrizes raciais. No entanto, o etnocentrismo torna-se perigoso quando transformado em uma arma ideológica a serviço do imperialismo".

De uma forma mais didática, é útil esclarecer que existem várias formas e manifestações de racismo, desde o preconceito, que é apenas um julgamento que se faz antecipadamente, passando pela discriminação, que é a forma de tratamento desigual, pela segregação, que é a separação física de grupos baseada no racismo, pelo molestamento, que é a agressão física por motivos raciais, até o genocídio, assassinato em massa de grupos raciais ou étnicos (LOPES, 2007).

$\mathrm{O}$ racismo também pode ser individual, institucional ou cultural. $\mathrm{Na}$ modalidade individual, estão socializados e mentalizados entre brancos, negros, mestiços e outros segmentos os mais diferenciados estereótipos e atitudes, aparecendo no cotidiano de variadas maneiras. Por exemplo, todas as mazelas e corrupções, maldades e desobediências são associadas à cor negra, ou melhor, preta, e frequentemente se manifestam por expressões pejorativas como: nuvem negra, mercado negro, câmbio negro, buraco negro, ovelha negra, lista negra, entre outras. E tais conceitos pejorativos também são criados contra os paraíbas, baianos, caipiras, favelados, gays etc. No racismo institucional, o negro, o índio, o judeu, o cigano, os retirantes, os boias-frias, os mendigos, os bêbados, os gigolôs, homossexuais, a mulher (principalmente se negra, pobre e favelada) e todos os 
grupos marginalizados (postos à margem da sociedade), destituídos e enjeitados são ocultos ou abertamente discriminados, seja na hora de conseguirem um emprego, terem acesso a serviço de saúde, educação, justiça, moradia, terem participação política etc. $\mathrm{Na}$ modalidade cultural do racismo, a evidência está na discriminação através da religião, da língua, da música, na filosofia, nos valores, na estética, nas crenças, nas necessidades etc. e pode aparecer sob a forma de leis, eliminando a manifestação cultural, como a provisão de 1727 que proibiu o bilinguismo no Brasil ou as leis que proibiam as praticas religiosas afro-brasileiras e a capoeira, vigentes até meados do século XX (SILVA, 1995).

Não podemos deixar de citar também o que Albert Memmi (2007) chama de racismo caridoso, que colore todas as ações chamadas paternalistas: uma vez que são superiores, os mais civilizados e os donos da patente da modernidade, o colonizador branco europeu e todos aqueles que ainda hoje adotam a atitude mental paternalista, sentindo-se possuidores da missão de civilizar o mundo e iluminar "as infames trevas" dos povos primitivos e atrasados (ou seja, todos aqueles a quem dominam e oprimem), realizam um bem por pura generosidade de sua alma, nunca por dever. Segundo Memmi (2007, p. 112), “o paternalista é aquele que, uma vez admitidos o racismo e a desigualdade, se pretende generoso para além deles". Se faz algo em benefício de um empregado, servo ou escravo, trata-se de doação, e nunca de dever, pois, se reconhecesse que tem deveres, precisaria admitir que o colonizado, servo, escravo ou empregado tem direitos.

No Brasil, todas essas diferentes formas de expressão do racismo se manifestam de maneira camuflada. É o que muitos autores têm chamado de racismo velado, estrategicamente camuflado pela ideologia do embranquecimento da população, geradora do Mito da Democracia Racial brasileira (LOPES, 2007; SANTOS; SILVA, 2005; SILVA, 1995).

A resistência intelectual e cultural a essa perspectiva histórica emergiu na América de diversas maneiras a partir do século XIX (embora haja registros de quilombos e mocambos desde o século XVII), afirmando-se com mais intensidade durante o século XX, em especial depois da Segunda Guerra Mundial, vinculada à luta por direitos civis e ao debate sobre a questão do desenvolvimento-subdesenvolvimento.

Movimentos sociais diversos e povos originários e tradicionais do mundo inteiro começaram a se organizar e denunciar a Colonialidade do Poder em suas diferentes expressões, do racismo à expropriação de terras, as desigualdades na distribuição dos riscos e danos ambientais gerados pelo modelo de desenvolvimento capitalista e eurocentrado, os quais produzem impactos diversos sobre etnias vulnerabilizadas, até mesmo a extinção de culturas. Muitos desses movimentos persistem ainda hoje em lutas contra a dominação dos colonizadores, opressores ou imperialistas, trabalhando para verem reconhecidas suas soberanias, assim como para verem reconhecidos e protegidos seus direitos, tratados, culturas e terras sagradas.

Um exemplo dessas lutas e organizações pode ser encontrado no Movimento por Justiça Ambiental, que, segundo Bullard (2006), surgiu entre os negros norte-americanos no final da década de 1970, liderado por um padre 
negro, o reverendo Benjamin Chavis. Em 1983, Chavis denunciou publicamente que era nos locais de moradia da população afrodescendente que se depositava o lixo tóxico produzido nos EUA. Chamaram isso de injustiça ambiental e fundaram o Movimento pela Justiça Ambiental.

No Brasil, o campo da justiça ambiental tomou forma durante o seminário em que nasceu a Rede Brasileira de Justiça Ambiental (RBJA), em 2001, a qual chamou de injustiça ambiental:

o mecanismo pelo qual sociedades desiguais, do ponto de vista econômico e social, destinam a maior carga dos danos ambientais do desenvolvimento às populações de baixa renda, aos grupos raciais discriminados, aos povos étnicos tradicionais, aos bairros operários, às populações marginalizadas e vulneráveis. [...] Uma lógica que faz com que todos os efeitos nocivos do desenvolvimento recaiam sempre sobre as populações mais vulneráveis. $(\mathrm{RBJA})^{8}$.

De fato, a distribuição desigual dos riscos, desvantagens e danos por classe social é uma consequência normal das economias capitalistas, racialmente estratificadas. Os mercados, geralmente livres para funcionar sem intervenção estatal, irão normalmente distribuir mercadorias e serviços com base na riqueza, já que o "moinho da produção", para parafrasear Gould (2004, apud WALLERSTEIN, 2001), gera tanto os benefícios econômicos como os malefícios ambientais. E, uma vez que os benefícios econômicos - a riqueza - da produção tendem a se concentrar nas camadas sociais mais altas, onde estão posicionados os dirigentes, proprietários, gerentes, investidores e políticos - os tomadores de decisão e os donos dos meios de produção -, inversamente, os danos e riscos ambientais gerados pela produção de mercadorias e de serviços tendem a se concentrar nas camadas inferiores do sistema. Pobres e classe trabalhadora, portanto, encontram-se sob maior risco, seja em casa, seja no trabalho, apesar de haver leis e artigos constitucionais que estabelecem o princípio da equidade e o direito ao meio ambiente sadio como um direito essencial. Nesse sentido, é muito próprio o conceito desenvolvido pelos sociólogos Giddens (1991) e Beck (1997) de que vivemos numa "Sociedade dos Riscos"9.

8 Para maiores detalhes ver o endereço eletrônico da RBJA: http://www.justiça ambiental.org.br

9 "No sentido de uma teoria social e de um diagnóstico de cultura, o conceito de sociedade de risco designa um estágio da modernidade em que começam a tomar corpo as ameaças produzidas até então no caminho da sociedade industrial" (BECK, 1992 p. 17). Para esse autor, o processo de industrialização é indissociável do processo de produção de riscos, uma vez que uma das principais consequências do desenvolvimento científico industrial é a exposição dos indivíduos a riscos e a inúmeras modalidades de contaminação nunca observados anteriormente, constituindo-se em ameaças para as pessoas e para o meio ambiente. Portanto, os riscos acompanham a distribuição dos bens, decorrentes da industrialização e do desenvolvimento de novas tecnologias. 
Assim, a RBJA surge com os objetivos de: 1) denunciar que a destruição do meio ambiente e dos espaços coletivos de vida e trabalho acontecem predominantemente em locais onde vivem populações negras, indígenas, tradicionais ou sem recursos econômicos e 2) fortalecer ações coletivas que possam se contrapor a esse processo. É apresentada como uma rede virtual, na realidade, como um fórum de discussões, de denúncias, de mobilizações estratégicas e de articulação política, principalmente com o propósito de ampliar e dar visibilidade às lutas encampadas por entidades e populações envolvidas ${ }^{10}$.

E cresceu tanto que, nos últimos anos, tornou a Justiça Ambiental um importante campo de estudos e pesquisas para diversas áreas do saber, em especial para as áreas das Ciências Sociais, do Direito e das Ciências Biológicas. É nesse campo que se inserem os estudos relativos aos conflitos socioambientais e ao racismo ambiental envolvendo perda de território (entre outros danos) das populações e comunidades tradicionais, devido à instituição de unidades de conservação da natureza em áreas de uso tradicional.

\section{Territorialidades do Poder: Áreas Protegidas e Injustiça Ambiental}

A criação de áreas protegidas por lei no mundo atual vem se constituindo numa das principais formas de intervenção governamental e visa reduzir as perdas da biodiversidade diante da degradação ambiental imposta pelo modelo de desenvolvimento de corte neoliberal e potencial altamente destruidor, que tem deixado suas marcas pelo mundo de maneira globalizada.

A instituição dessas áreas decorre da crença clássica do pensamento ambientalista preservacionista, de ideologia eurocentrista, hegemônico no campo da conservação e que afirma existir uma relação inversa entre ações humanas e o bem-estar do ambiente natural. O mundo natural e o mundo urbano são vistos, nessa perspectiva, como uma oposição. Montanhas, desertos, florestas e demais espaços de vida selvagem formam um conjunto que é considerado "natureza", área desenvolvida e mantida apenas na ausência de seres humanos. De fato, segundo o Wilderness Act, decreto norte-americano de preservação da vida selvagem, de 1964, natureza é definida como um lugar "onde o próprio homem é um visitante que não permanece" (GOMEZ-POMPA; KLAUS, 2000, p. 127).

O estabelecimento de áreas protegidas a partir de 1864 na Califórnia (na região de Yosemite Valley e Mariposa Grove), seguido pela criação do Yellowstone National Park, em 1872, deu a essa vertente do ambientalismo uma clara dimensão territorial, na qual se consagrou o valor da apreciação da natureza no seu estado "intocado" (DIEGUES, 1998; LITTLE, 2002; MILLER, 1997; THOMAS, 1988 [1983]).

No século e meio seguinte, áreas protegidas por lei se expandiram por todas as partes do mundo, especialmente a categoria Parque Nacional (categoria de uso indireto dos recursos naturais), que tem sido, desde então, o modelo dominante. Historicamente, a criação de Parques Nacionais teve por finalidade a preservação

${ }^{10}$ Para maiores detalhes ver http://www.justicaambiental.org.br. 
dos espaços naturais ditos intocáveis ou selvagens (wildernesses), idealizados como grandes e extensas áreas naturais sem população que possuíssem paisagens de extrema beleza cênica, destinadas à recreação de elites urbanas sedentas de paz e consolo das desventuras do mundo moderno das cidades. Apenas há trinta anos fala-se em proteção da biodiversidade como um dos objetivos da criação de Parques Nacionais. Paul Little (2002, p. 16) chama essa vertente do ambientalismo de "preservacionismo territorializante" devido à centralidade do controle total sobre extensas áreas geográficas na atuação de seus militantes.

Para preservar sua riqueza natural, o Brasil segue a tendência mundial de criar áreas naturais protegidas legalmente instituídas, entre as quais se destacam as Unidades de Conservação da Natureza, cujo principal marco legal foi estabelecido no ano 2000, com a criação do Sistema Nacional de Unidades de Conservação da Natureza (SNUC), através da Lei 9.985/2000. Nesse sistema, coexistem Unidades de Proteção Integral (como os Parques e Reservas Biológicas), onde apenas é permitido o uso indireto dos recursos naturais, e Unidades de Uso Sustentável (como as Reservas Extrativistas), onde o uso direto é permitido segundo regras preestabelecidas.

Como as Unidades de Conservação de Uso Indireto não permitem a presença de populações humanas dentro de seus territórios, sendo isso na visão antropológica uma de suas regras cosmográficas mais firmes, a solução inicialmente encontrada pelos preservacionistas, e legitimada em leis, decretos e portarias, foi a expulsão desses grupos populacionais dos "novos" territórios preservacionistas, seja por indenização, seja por reassentamento compulsório, tal como tem sido feito com as construções de hidroelétricas, mineradoras, estradas e os outros grandes projetos de desenvolvimento. Os preservacionistas renomearam esses habitantes "populações residentes", "permanentes" ou "locais" (INSTITUTO SOCIOAMBIENTAL, 2001; LITTLE, 2002), categorizando-os assim em função da lógica instrumental das novas áreas protegidas e, nesse processo, ignorando a existência prévia de regimes de propriedade coletiva, relações afetivas desses povos com o seu lugar de origem e memórias coletivas sobre esses mesmos espaços. Por isso, Little (2002, p. 16) considera as áreas protegidas como um braço desenvolvimentista dos governos baseado nas noções de controle e planejamento.

Nesse sentido, as áreas protegidas representam um tipo específico de território que, segundo as definições de Quijano (1988), se enquadraria na noção de razão instrumental do Estado por três motivos: em primeiro lugar, as áreas protegidas são criadas pelo Estado mediante decretos e leis e conformam parte das chamadas Terras da União, sendo, portanto, terras públicas; em segundo lugar, a criação dessas áreas inclui sofisticadas pesquisas científicas que envolvem um grande número de especialistas, o que mostra o alto grau de conhecimento humano e cientificismo implicado nelas; em terceiro lugar, as áreas protegidas estabelecem regras em seus planos de manejo que especificam com minuciosos detalhes as atividades permitidas e proscritas dentro desses territórios.

Essa razão instrumental tem se confrontado com a razão histórica dos povos tradicionais em todo o planeta (DIEGUES, 1998; LITTLE, 2002) e tem se 
constituído em novo instrumento de dominação e controle racial, mantendo uns e segregando outros, de acordo com sua lógica de base ideológica eurocentrista e racialmente excludente.

Por isso, o processo de criação de parques e outras unidades de conservação tem sido acompanhado de diversas modalidades de conflitos em várias partes do mundo, em especial na América Latina, onde estudos mostraram que 86\% das áreas protegidas são habitadas (AMED; AMED, 1992; KEMF, 1993). Em âmbito mundial, de acordo com dados da IUCN para 1985 , cerca de $70 \%$ das áreas protegidas eram habitadas (DIXON; SHERMAN, 1991 apud COLCHESTER, 2000).

Por conflito socioambiental entende-se um tipo de conflito social que expressa uma luta entre interesses diferentes (opostos ou não) que disputam o controle dos recursos naturais e o uso do meio ambiente comum (ACSELRAD et al., 1995). O estudo dos conflitos procura "captar o conteúdo específico das disputas que têm os elementos da natureza como objeto e que expressam relações de tensão entre interesses coletivos/espaços públicos $\mathrm{X}$ interesses privados/tentativas de apropriação de espaços públicos" (SCOTTO; LIMONCIC, 1997, p. 19).

No Brasil, a criação de unidades de conservação pela ação de governos implica, muitas vezes, a expulsão de povos tradicionais de suas terras (mais que isso, de seu território), agora transformadas em terras públicas para a preservação da natureza selvagem e da diversidade biológica a ela associada, gerando inúmeros conflitos, já que tais povos ficam impedidos de reproduzir seus modos tradicionais de vida.

Para esclarecer melhor a profundidade do que isso significa, é preciso lembrar como se estrutura o regime formal de terras no Brasil. De modo geral, a terra é dividida em duas categorias básicas: terras privadas e terras públicas. As terras privadas são presididas pela lógica capitalista e individualista, segundo a qual o dono consegue o direito mediante: 1) o controle exclusivo sobre a parcela que lhe pertence, 2) a sua exploração para fins econômicos, 3) a sua venda e 4) a reivindicação judicial da propriedade se ela estiver injustamente em poder de outro (BRITO, 2000). A noção de terras públicas, por outro lado, é associada diretamente com o controle da terra por parte do Estado. Nessa concepção, a terra pertence, ao menos formalmente, a todos os cidadãos do país, porém, é o aparelho do Estado que determina os usos dessas terras, supostamente em benefício da população em seu conjunto. Ou seja, a terra é de todos, mas quem manda é o Estado (capitalista, racista e eurocentrado em sua base). Na realidade, esses usos tendem a beneficiar alguns grupos de cidadãos e, ao mesmo tempo, prejudicar outros. Consequentemente, o usufruto particular das terras públicas se converte numa luta pelo controle do aparelho do Estado ou, no mínimo, pelo direcionamento de suas ações em benefício de um ou outro grupo específico de cidadãos (LITTLE, 2002).

Isso pode ser visto no caso das áreas protegidas de usufruto indireto, como os parques nacionais, em que um grupo articulado de cientistas, pesquisadores e fiscais ligados ao órgão gestor tem permissão de acesso, uso e mesmo controle 
dos recursos das unidades diferenciados de outros grupos. São os únicos com permissão de matar (espécies daninhas, invasoras, exóticas, para inventário de fauna e flora, para controle de população etc.), por exemplo. Ou de multar, prender e aplicar demais sanções administrativas e legais previstas na Lei de Crimes Ambientais (Lei 9605/98) e nos seus dois decretos regulamentadores.

Para Quijano (1988), os conceitos de privado e público, tal como são usados atualmente na América Latina, mantêm as sociedades latino-americanas presas a esquemas que não correspondem às necessidades de seus diversos membros nem à sua realidade quotidiana. O binômio privado-público, para Quijano (1988, p. 24), representa "duas caras da mesma razão instrumental, cada uma encobrindo a dos agentes sociais que competem pelo lugar de controle do capital e do poder: a burguesia e a burocracia”. Em contraposição à razão instrumental, Quijano (1988, p. 17) identifica uma razão histórica que, embora subordinada à razão instrumental, continua possuindo uma forte presença entre os povos marginalizados pelos sistemas atuais de poder e "age como resistência contra o poder existente".

No caso dos povos tradicionais do Brasil, as distintas formas de propriedade geradas pelas diferentes etnias e populações tradicionais as afastam da razão instrumental hegemônica, cujo regime de propriedade é baseado na dicotomia entre o privado e o público. Todavia, como nota Little (2002, p. 7),

[..] a razão histórica a elas subjacente incorpora alguns elementos que muitas vezes são considerados como públicos - isto é, bens coletivos -, mas que não são tutelados pelo Estado. Por outro lado, também incorpora elementos comumente considerados como privados, no caso de bens (materiais ou simbólicos) pertencentes a um grupo específico de pessoas, mas que existem fora do âmbito do mercado.

Como os territórios desses grupos se fundamentam, segundo a razão instrumental, no arcabouço da lei consuetudinária hoje vigente no país (e raras vezes reconhecida e respeitada pelo próprio Estado), as articulações entre esses grupos são marginais aos principais centros de poder político. Ou seja, embora tenham "direitos", os povos tradicionais acabam sendo expulsos de suas terras/territórios.

Agora que já há mais elementos para uma análise mais profunda, podemos entrar diretamente no conceito de racismo ambiental, outro tema dos mais discutidos no campo de debates e estudos ligados à Justiça Ambiental, sendo atualmente discutido por diferentes escolas de pensamento em diferentes países do mundo e tendo mesmo se convertido em política pública ao tornar-se um programa de ação do governo federal dos Estados Unidos, através da EPA, agência de proteção ambiental norte-americana (MADEIRA FILHO, 2002).

No Brasil, o Racismo Ambiental diz respeito "às injustiças sociais e ambientais que recaem de forma desproporcional sobre etnias vulnerabilizadas" (HERCULANO; PACHECO, 2006, p. 25). E esse racismo não está restrito 
apenas a práticas e ações que tenham tido intenção racista, engloba as que igualmente causem impacto racial, não importando a intenção que as originou. Isso amplia tanto o número como os tipos de casos de racismo ambiental praticados no país, incluindo os do campo da conservação da natureza, em que grupos étnicos em estado de vulnerabilidade são removidos, expulsos e descartados de seus territórios de origem, pertencimento e identidade por ações de governos, que reterritorializam nos mesmos espaços de uso tradicional empresas capitalistas (para atender ao mercado, ao desenvolvimentismo e à modernização do país) ou unidades de conservação da natureza (para a preservação da diversidade biológica, recreação em contato com a natureza e pesquisa científica).

Os grupos humanos expulsos de suas áreas de uso tradicional costumam ser agrupados pela lógica instrumental da Conservação (seja por estudos e pesquisas, seja por leis, decretos, planos e outras políticas públicas) sob diversas categorias - populações, comunidades, povos, sociedades, culturas, grupos -, cada uma das quais costuma estar acompanhada por um dos seguintes adjetivos: tradicionais, tribais, autóctones, rurais, locais, permanentes, residentes (nas áreas protegidas) (BARRETO FILHO, 2001 apud LIT'TLE, 2002 p. 2; VIANNA, 1996).

Assim, o estudo e a pesquisa sobre racismo ambiental, no Brasil e no mundo, envolvem não apenas grupos negros ou indígenas mas também outras identidades culturais, tais como pescadores, caiçaras, caipiras, jangadeiros, populações ribeirinhas, marisqueiros, catadores de coco de babaçu, camponeses, catadores de sementes, extrativistas, entre outras, que de uma perspectiva marxista estão associadas a modos de produção pré-capitalistas, próprios de sociedades em que o trabalho ainda não se tornou mercadoria.

Um elemento importante na ligação entre essas populações e a natureza é sua relação com o território, que é definido por Godelier (1984) como:

uma porção da natureza e do espaço sobre o qual determinada sociedade reivindica e garante a todos, ou a uma parte de seus membros, direitos estáveis de acesso, controle ou uso na totalidade ou parte dos recursos naturais existentes, fornecendo ao homem os meios necessários a sua subsistência, os meios de trabalho e produção, e os meios para a produção dos aspectos materiais e imateriais (simbólicos) das relações sociais.

Além de espaço de reprodução econômica das relações sociais, o território é o lugar das representações mentais e do imaginário mitológico dessas sociedades, sendo importante analisar o sistema de representações, símbolos e mitos que essas populações constroem, pois é com ele que agem sobre o meio natural e desenvolvem seus métodos tradicionais de manejo (DIEGUES; ARRUDA, 2001).

Nesse sentido, o território, para as comunidades e povos tradicionais, diferentemente daquele das sociedades urbano-industriais, muitas vezes é descontínuo, marcado por vazios aparentes (terras em pousio, áreas de coleta, de 
caça, áreas para rituais etc.), sendo a propriedade coletiva e comunal. Esse é um dos fatos que têm levado o Estado-Nação brasileiro a transformar essas áreas em unidades de conservação, uma vez que "não são de ninguém”, ou "não são usadas por ninguém", daí resultando conflitos entre autoridades conservacionistas e comunidades tradicionais.

Entre os casos principais e mais conhecidos de conflitos estão os de superposição entre Terras Indígenas e os Parques Nacionais do Araguaia (TO), Monte Pascoal (BA), Superagüi (PR) e Pico da Neblina (AM), para citar apenas alguns. Essas situações colocaram os órgãos ambientais do Estado contra esses povos, que, repentinamente, foram proibidos de realizar suas atividades habituais de uso do meio biofísico para sua subsistência. O caso das comunidades de remanescentes de quilombos do rio Trombetas é outro exemplo: os quilombolas se encontraram em situação igualmente constrangedora com a criação da Reserva Biológica do Rio Trombetas e de uma Floresta Nacional, além da instalação de uma mineradora, em suas áreas tradicionais de usufruto, de tal forma que o IBAMA se tornou para os quilombolas "o símbolo do poder opressor do Estado, criando obstáculos para a utilização tradicional dos recursos naturais de seu território, ao mesmo tempo que facilitava a exploração desse território pelos mineradores privados e preservacionistas estatais" (ACEVEDO; CASTRO, 1998; O’DWYER, 2006, p. 53-72).

Outros casos ilustrativos envolvem os índios caiovás e guaranis de Mato Grosso do Sul, que há 200 anos sofrem com os diversos processos de ocupação de seu território empreendidos pelo Estado brasileiro, e o caso dos povos de santo e comunidades de terreiros envolvendo o Parque Nacional da Tijuca (PNT), no Rio de Janeiro, compostos por comunidades religiosas de matrizes africanas (como o candomblé e a umbanda), cuja presença é registrada na região desde o século XVII e que têm seu acesso às áreas da unidade restrito ou mesmo impedido devido às práticas religiosas que realizam, sofrendo discriminação e constrangimentos diversos.

Importante ressaltar que no caso envolvendo o PNT a discriminação e a desigualdade no uso dos espaços públicos da unidade ocorrem de maneira tão naturalizada que exemplificam, com maestria, tanto o racismo velado como a Colonialidade do Poder que ainda impera no país. Das quatorze religiões identificadas pelo parque como usuárias ${ }^{11}$, apenas a católica (que é hegemônica no país) conta com permissão prévia para realizar seus diferentes rituais (casamentos, batizados, missas e bodas) e infraestrutura adequada para receber os visitantes religiosos e realizar suas práticas, o que inclui lugares/templos sagrados (no caso, as Capelas Mayrink e Silvestre, o Cristo Redentor e a Capela de Nossa Senhora Aparecida, no Corcovado), coletores de lixo em todos os ambientes, coleta regular de resíduos (realizada por empresa terceirizada nas áreas internas e pela empresa de coleta pública urbana - Comlurb - nas áreas

11 Pela Oficina de Práticas Religiosas em Áreas Protegidas, organizada pela DIREC/IBAMA e pelo PNT em 2005, no âmbito da Revisão do Plano de Manejo da unidade. 
externas), áreas para acenderem velas e colocarem demais artefatos da ritualística (candelabros, taças e jarros para vinho, panos, Bíblia e recipientes para a hóstia), áreas para estacionamento, iluminação e segurança. As outras treze religiões não católicas identificadas como usuárias, frequentadoras ou visitantes necessitam de permissão prévia da administração do parque para realizarem seus rituais (de modo a cumprir a exigência do Art. 37, Decreto 84.017/79), não contam com infraestrutura adequada para suas práticas, não contam com um lugar previamente organizado e estruturado, com coletores de lixo, sistema de coleta regular de resíduos, áreas para uso de velas, áreas preestabelecidas para oferendas, estacionamento, iluminação e segurança. Pior, muitas (principalmente aquelas relacionadas à população negra) são acusadas de poluidoras e agentes de degradação, identificadas como ameaça e tratadas como caso de polícia ${ }^{12}$.

Tais exemplos mostram que esses grupos sociais têm sido impactados não apenas por projetos de cunho desenvolvimentista mas também pela instituição de áreas protegidas, que igualmente afetam e atingem o modo de organização e de vida dessas populações e comunidades tradicionais, suas identidades culturais e as relações tradicionais que estabeleceram com seus territórios de origem e identidade. Segundo Brand (2006, p. 88-99), "mais do que alterar seus modos de vida, tais projetos comprometeram, de forma crescente, a autonomia desses povos".

Nesse contexto, pode-se dizer que o governo brasileiro, através do Ministério do Meio Ambiente (e este através do IBAMA, que após a MP 366-07 foi descentralizado em Instituto Chico Mendes de Biodiversidade - ICMBio), com a prática de instituir áreas protegidas, pode incorrer em injustiça ambiental e praticar racismo ambiental, uma vez que tais ações atingem etnias vulnerabilizadas, desterritorializando-as ${ }^{13}$ de seus locais de origem, de pertencimento e identidade, causando impactos diversos sobre seus modos de vida. Nesse sentido, para Little (1992), as áreas protegidas representam, na verdade, uma vertente desenvolvimentista dos governos, baseada nas noções de controle e planejamento.

Tais práticas têm se constituído num enorme problema para os governos que as adotam, não apenas pela crescente judicialização dos conflitos como pelos altos custos gerados pelas indenizações e reassentamentos das populações expulsas. Outra razão é a baixa efetividade que os modelos adotados de conservação têm tido na proteção da diversidade biológica e que tem sido exposta por inúmeras pesquisas no campo das Ciências Sociais, principalmente (DIEGUES, 2000; DIEGUES; ARRUDA, 2001).

\section{Socioambientalismo e Diversidade Biocultural: Conservação com Justiça Social}

Há uma corrente do ambientalismo mundial, surgida em meados do século $\mathrm{XX}$, que acredita que culturas e saberes tradicionais podem contribuir para a

12 Para maiores detalhes do conflito ver Moutinho-da-Costa (2008).

13 Sobre o conceito de desterritorialização ver Haesbaert (2001, 2004, 2006). 
manutenção da biodiversidade dos ecossistemas - é o socioambientalismo, respaldado pela Ecologia Social, um campo do conhecimento que associa saberes ecológicos com justiça social.

O termo "ecologia social" foi usado pela primeira vez pelo sociólogo indiano Radhakamal Mukerjee, em 1942. O princípio central da ecologia social (modelo indiano) é que as sociedades tidas como tradicionais têm longa tradição de interação com o hábitat, usando somente tecnologias que emergiram naquele hábitat. Tais sociedades desenvolveram práticas culturais de utilização dos recursos naturais que levaram à sustentabilidade das áreas onde vivem (GUHA, 2000; SARKAR, 2000).

Muitos ecólogos sociais indianos, como Mahdhav Gadgil, têm desenvolvido estudos que, na contramão do proposto pela Biologia da Conservação, corrente ocidental, mostram que algumas atividades humanas aumentam a diversidade biológica e trabalham as implicações disso para as estratégias de conservação ${ }^{14}$.

Para a ecologia social, o problema mais urgente é que o modo de vida tradicional está sendo cada dia mais desorganizado, seja pela expropriação dos recursos locais, pelo uso de tecnologias modernas e destrutivas, perda de controle tradicional dos hábitats, entre outras práticas ligadas à expansão da Colonialidade do Poder, cujos principais protagonistas têm sido os colonizadores, desenvolvimentistas e os preservacionistas, que transformam hábitats vivos em reservas e áreas "selvagens", todos agindo com autoridade opressiva e coerciva (SARKAR, 2000).

Consequentemente, na perspectiva da Ecologia Social, a luta política pelos direitos dos povos tradicionais é também um programa para a conservação da diversidade biológica, na medida em que esses saberes e fazeres contribuem para a manutenção dessa diversidade. Em numerosas situações, esses saberes são, na verdade, o resultado de uma coevolução entre as sociedades e seus ambientes naturais, o que permitiu um equilíbrio dinâmico entre ambos ao longo do tempo. Tais culturas e saberes estão ligados ao modo tradicional de vida das chamadas "etnicidades ecológicas".

O conceito de "etnicidade ecológica" é posterior ao de "povos dos ecossistemas" (ecosystem peoples), de que trata Dassmann (1988), e foi cunhado em 1996 pelo indiano Pramod Parajuli (2006). Sob o guarda-chuva da etnicidade ecológica, o autor inclui mais de 500 milhões de nativos espalhados pelo mundo, talvez 2 milhões de camponeses e outros grupos sociais que, segundo Gary Paul Nabhan (1987 apud PARAJULI, 2006, p. 100), vivem em culturas de hábitat,. Nessa categoria os indígenas formam uma parte importante, mas não são o elemento único constituinte das etnicidades ecológicas. Nela o autor inclui pescadores, guardadores de sementes, habitantes das florestas, pastores nômades,

14 Gadgil e seus colaboradores argumentaram que em muitas regiões da Índia práticas religiosas tradicionais podem ajudar a preservar a diversidade biológica e que as práticas tradicionais de manejo podem evitar a destruição de espécies (SARKAR, 2000, p. 59). 
caçadores e coletores, bem como outras tantas comunidades e grupos culturais tradicionais.

A noção de etnicidade ecológica refere-se a qualquer grupo de pessoas que deriva seu sustento e sobrevivência (material ou cultural) da negociação cotidiana com o ambiente imediato. Seu modo de usar a natureza e de criar diversidade biocultural é distinto daqueles que podem ser considerados como pessoas biosféricas, no sentido de que, ao contrário das etnicidade ecológicas, obtêm e usam, extraem e consomem seus recursos de todo o globo e não dependem dos constrangimentos do ecossistema, de seus ciclos, movimentos, fases, épocas, estações.

Segundo o referido autor, a etnicidade hoje em dia se produz e se reproduz no âmbito do que ele chama de diversidade biocultural, definida por ele como uma propriedade da natureza, uma prática de cultivar uma totalidade de espécies, populações e comunidades, tanto selvagens quanto domésticas, que constituem a vida de qualquer ecossistema ou bioma. Ou seja, assim como produz passarinhos e árvores, a natureza produz cultura e etnicidades.

Para ilustrar esse conceito, Parajuli apresenta dados de um estudo em que seis dos nove países nos quais $60 \%$ das 6.500 línguas remanescentes do mundo são faladas aparecem também como centros de megadiversidade. Esses seis países são: México, Brasil, Indonésia, Índia, Zaire e Austrália. Além disso, na superposição dos 25 países com maior número de línguas endêmicas, 16 deles também tinham o número mais alto de espécies selvagens endêmicas.

Em termos globais, há 10 mil grupos identificados com base na etnia, na língua e na religião, espalhados por mais de 168 Estados-Nações. Apesar de diminuídas, há ainda 6.500 línguas orais sendo usadas hoje do total de 15 mil línguas fortes existentes quando Colombo navegou para o Novo Mundo em 1492. E, para continuar existindo, pois se encontra severamente ameaçado hoje, esse mosaico da diversidade biocultural mundial necessita de mais atenção de todos os países, uma vez que o modelo mundializado de Parque Nacionais (grandes áreas "selvagens" e sem moradores) pensa a proteção da biodiversidade excluindo a presença humana, que é na realidade a maior responsável por essa riqueza.

O que é importante nisso é ser reconhecido que tal abundância não é um ato da natureza apenas, é realmente o resultado de milhares de anos de inovações humanas e de relação interdependente com a natureza. Noorgard (1994) chama isso de coevolução, que pode ser entendida como uma síntese interativa dos mecanismos de mudança social e natural.

Trabalhos recentes nas Ciências Sociais reforçam essa argumentação ao compreenderem as áreas naturais como construções humanas - "artefatos", na terminologia de Barreto Filho (2001) - , e não simplesmente como áreas naturais selvagens e intocáveis, como preconiza a visão eurocentrista e hegemônica dos preservacionistas. A ideia, por exemplo, de que a Amazônia seria a última e mais vasta região de floresta tropical intocada e selvagem que ainda subsiste no mundo tem sido amplamente contestada pelos trabalhos de ecologia histórica. Segundo Descola (2000, p. 150), tais estudos têm mostrado que a abundância 
dos solos antropogênicos e sua associação com florestas de palmeiras ou de árvores frutíferas silvestres sugerem que a distribuição dos tipos de floresta e de vegetação na região resulta, em parte, de vários milênios de ocupação por populações cuja presença recorrente nos mesmos sítios transformou profundamente a paisagem vegetal, "de modo que a natureza amazônica é, na verdade, muito pouco natural, podendo ser considerada, ao contrário, o produto cultural de uma manipulação muito antiga da fauna e da flora". Isso se deve ao fato de que as populações indígenas da Amazônia (Brasil e Guianas) souberam aplicar estratégias de uso dos recursos que não alteravam os princípios de funcionamento nem punham em risco as condições de reprodução desse ecossistema.

Ademais, isso aponta a necessidade de se abandonar o mito/crença/dogma de que apenas as áreas limpas e plantadas são manejadas, de se repensar o que significa "natureza selvagem" e "hábitat não modificado" e de modificar o entendimento de que a vegetação madura representa uma comunidade no seu clímax, ou seja, num final estável que reflete a ordem da natureza sem interferência humana, podendo ser na realidade um legado das populações passadas.

Para Gomez-Pompa e Kaus (2000, p. 133-134), a questão não se refere simplesmente à presença ou à densidade dos humanos em áreas naturais, que a Biologia da Conservação tanto persegue e combate, mas aos instrumentos, tecnologias, técnicas, conhecimentos e experiências que acompanham o sistema de produção de uma determinada sociedade. As comunidades e povos tradicionais são normalmente mais fortemente ligados ao meio ambiente local e mais dependentes dos recursos locais para a sua subsistência. Em contraste, os sistemas modernos de produção das sociedades urbano-industriais capitalistas possuem tecnologias avançadas, desde venenos químicos (chamados de fertilizantes) até bombas atômicas, que são externos e estranhos ao meio ambiente no qual se inserem. E essas tecnologias têm potencial altamente destruidor, capazes de impor sobre o meio ambiente transformações irreversíveis e imprevisíveis pelo conhecimento tradicional, de maneira que há hoje a capacidade de destruir o meio ambiente em escala muito maior do que jamais se viu na história da humanidade.

Assim, quando se fala em proteger hábitats que não sofreram ainda distúrbios, os chamados ecossistemas virgens e intocados, é importante deixar claro que o termo "não modificado" se refere à ausência de distúrbios causados por tecnologias modernas, ligadas a sociedades urbanas e industriais. Portanto, não seria a presença de populações humanas a grande culpada pela degradação ambiental e extinção de espécies diversas, mas a presença dos "povos biosféricos", mencionados por Dassmann (1988) e Parajuli (2006), sociedades interligadas a uma economia global, de alto consumo e poder de transformação da natureza e que provocam grande desperdício de recursos naturais.

O importante deste relato é reconhecer que em outras sociedades, sistemas, crenças e práticas culturais existem tradições de conservação distintas da conservação tradicional do Ocidente, firmemente enraizada nos ideais e modelos 
eurocentristas do Sistema-Mundo Capitalista, e que tais ideais e modelos não têm sido eficientes em manter conservados os ecossistemas que se pretende proteger.

Nesse contexto, para se enfrentar e superar a "crise da conservação" mencionada por Diegues (1996), dois caminhos têm sido propostos em nível mundial pela Ecologia Social: 1) superar o modelo hegemônico gerador tanto das assimetrias racistas sociais e dos danos ambientais quanto da oposição homemnatureza, assim como a racionalidade e os paradigmas a ele associados; 2) estreitar os elos entre a diversidade cultural e a diversidade biológica, começando por incorporar as primeiras nos objetivos, instrumentos e estratégias da segunda, de maneira que se promova a conservação tanto do patrimônio natural como do patrimônio cultural, material e imaterial dessas áreas, ou seja, para que se promova a "biossocioconservação", ou conservação da "diversidade biocultural", abordada por Parajuli (2006) e na qual a cultura/homem é vista como aliada(o), e não como inimiga(o).

Apesar de haver ainda muito o que fazer, o Brasil já possui alguns instrumentos legais e constitucionais, iniciativas e ferramentas pedagógicas nesse sentido, fruto do ativismo socioambientalista e da educação ambiental crítica, que podem abrir muitas frentes e possibilidades, como a metodologia Educação no Processo de Gestão Ambiental, criada pela antiga Coordenação Geral de Educação Ambiental do IBAMA (QUINTAS, 2002, 2005); os regimes de cogestão, ou a gestão participativa das unidades de conservação, possibilidade aberta pela Lei 9.985/2000, que institui o Sistema Nacional de Unidades de Conservação; o Plano Nacional Estratégico de Áreas Protegidas (PNAP), estabelecido pelo Decreto 5.758/06, e a Política Nacional de Desenvolvimento Sustentável dos Povos e Comunidades Tradicionais, Decreto n ${ }^{\circ}$ 6.040, de 07 de fevereiro de 2007, para citar apenas alguns exemplos. As publicações do Instituto Socioambiental (ISA) e as da CLACSO são também boas indicações. Tais instrumentos e iniciativas, agora, necessitam ser mais conhecidos e apropriados por todos aqueles que pretendem realizar uma conservação da natureza com face humana, ou seja, conservação com dignidade e justiça social.

\section{Referências}

ACEVEDO, R.; CASTRO, E. Negros do Trombetas: Guardiões de matas e rios. 2. ed. revista e ampliada. Belém: Cejup/UFPA, 1998.

ACSELRAD, H. et al. Conflitos Sócio-Ambientais no Brasil. Rio de Janeiro: IBASE, 1995. (v. 1).

AMED, S.; AMED, T. (Ed.). Espacios sin habitantes? Parques Nacionales de América del Sur. Caracas: IUCN, 1992.

BARRETTO FILHO, H. T. Da nação ao planeta através da natureza: uma abordagem antropológica das unidades de conservação de proteção integral na Amazônia brasileira. 2001. Tese (Doutorado em Antropologia Social) - Universidade de São Paulo, 2001.

BECK, U. Risk Society: Towards a New Modernity. New Delhi: Sage, 1992. 
A Reinvenção da Política. In: GIDDENS, A.; BECK, U.; LASH, S. (Org.). Modernização Reflexiva: política, tradição e estética na ordem social moderna. São Paulo: Unesp, 1997. p. 45-69.

BRAND, A. Racismo, conflitos socioambientais e cidadania. In: HERCULANO, S.; PACHECO, T. (Org.). Racismo Ambiental. I Seminário Brasileiro contra o Racismo Ambiental. Rio de Janeiro: FASE, 2006. p. 88-99.

BRITO, M. C. W. Unidades de Conservação: intenções e resultados. São Paulo: Annablume; Fapesp, 2000.

BULLARD, R. D. Varridos pelo Furacão Katrina: reconstruindo uma "nova" Nova Orleans usando o quadro teórico da justiça ambiental. In: HERCULANO, S.; PACHECO, T. (Org.). Racismo Ambiental. I Seminário Brasileiro contra o Racismo Ambiental. Rio de Janeiro: FASE, 2006. p. 126-147.

CLAY, J. Parks and People. Cultural Survival Quarterly, v. 9, n. 1, p. 2-7, Feb. 1985.

COLCHESTER, M. Resgatando a Natureza: Comunidades Tradicionais e Áreas Protegidas. In: DIEGUES, A. C. (Org.). Etnoconservação: novos rumos para a Conservação da Natureza. 2. ed. São Paulo: Hucitec, 2000. p. 225-256.

DASSMANN, E. Toward a biosphere consciousness. In: WORSTER, D. (Ed.). The ends of the Earth: perspectives on modern environmental history. Cambridge: Cambridge University Press, 1988. p. 277-288.

DEAN, Warren. A Ferro e Fogo: a história e a devastação da mata atlântica brasileira. São Paulo: Companhia das Letras, 1997.

DESCOLA, P. Ecologia e Cosmologia. In: DIEGUES, A. C. (Org.). Etnoconservação: novos rumos para a Conservação da Natureza.. 2. ed. São Paulo: Hucitec, 2000.

DIEGUES, A. C. O Mito Moderno da Natureza Intocada. São Paulo: Hucitec, 1996. . (Org.). Etnoconservação: novos rumos para a Conservação da Natureza. 2. ed. São Paulo: Hucitec, 2000.

DIEGUES, A. C.; ARRUDA, R. S. V. Saberes tradicionais e biodiversidade no Brasil. Brasília: Ministério do Meio Ambiente, 2001.

DOWIE, M. Conservation Refugees: When Protecting Nature Means Keeping People Out. Orion, 2005. Available from: <http://www.orionmagazine.org>. Cited: 15 abr. 2011.

GIDDENS, A. As Conseqüências da Modernidade. São Paulo: Unesp, 1991.

GODELIER, M. L'idéel et le matériel. Paris: Fayard, 1984.

GOMEZ-POMPA, A.; KLAUS, A. Domesticando o Mito da Natureza Selvagem. In: DIEGUES, A. C. (Org.). Etnoconservação: novos rumos para a Conservação da Natureza. 2. ed. São Paulo: Hucitec, 2000.

GUHA, R. O Biólogo Autoritário e a Arrogância do Anti-humanismo. In: DIEGUES, A. C. (Org.). Etnoconservação: novos rumos para a Conservação da Natureza. 2. ed. São Paulo: Hucitec, 2000. p. 81-99. 
HAESBAERT, R. Território, cultura e des-territorialização. In: ROSENDAHL, Z.; CORRÊAA, R. L. (Org.). Religião, identidade e território. Rio de Janeiro: EdUERJ, 2001. p. 115-144.

O mito da desterritorialização: do "fim dos territórios" à multiterritorialidade. Rio de Janeiro: Bertrand Brasil, 2004.

. Concepções de território para entender a desterritorialização. In: SANTOS, M.; BECKER, B. Território, territórios: ensaios sobre o ordenamento territorial. Rio de Janeiro: DP\&A, 2006.

HERCUlANO, S.; PACHECO, T. (Org.). Racismo Ambiental. I Seminário Brasileiro contra o Racismo Ambiental. Rio de Janeiro: FASE, 2006.

INSTITUTO SOCIOAMBIENTAL. Povos indígenas no Brasil: 1996/2000. São Paulo: 2001.

KEMF, E. (Org.) Indigenous Peoples and Protected Areas: The Law of Mother Earth. London: Earthscan, 1993.

LANDER, E. (Org.). A colonialidade do saber: eurocentrismo e ciências sociais perspectivas latino-americanas. Buenos Aires: CLACSO, 2005.

9, n. 9, 1997.

Colonialidad, modernidad, posmodernidad. Anuário Mariateguiano, Lima, Peru, v.

LITTLE, P. E. Territórios Sociais e Povos Tradicionais no Brasil: por uma antropologia da territorialidade. Brasília: UnB, 2002. (Série Antropológica, n. 322).

. Ecología Politica del Cuyabeno: el Desarrollo No Sostenible de la Amazonía. Quito: ILDIS; Abya-Yala, 1992.

LOPES, N. O Racismo explicado aos meus filhos. Rio de Janeiro: Agir, 2007.

MADEIRA FILHO, W. (Org.). Direito e Justiça Ambiental. Niterói: PPGSD, 2002.

MARX, K. O Capital: crítica da economia política. 23. ed. Rio de Janeiro: Civilização Brasileira, 2006. (Tomo 1).

MEMMI, A. Retrato do colonizado precedido de retrato do colonizador. Rio de Janeiro: Civilização Brasileira, 2007.

MILLER, K. R. Evolução do conceito de áreas de proteção: oportunidades para o século XXI. In: CONGRESSO BRASILEIRO DE UNIDADES DE CONSERVAÇÃO, 1. 1997, Curitiba. Anais... Curitiba: IAP, 1997. v. 1, p. 3-21.

MOUTINHO-DA-COSTA, L. A Floresta Sagrada da Tijuca: estudo de caso de conflito envolvendo uso público religioso de parque nacional. 2008. Dissertação (Mestrado) Instituto de Psicologia, Universidade Federal do Rio de Janeiro, Rio de Janeiro, 2008.

MUNANGA, K. Raízes científicas do mito do negro e o racismo ocidental. Temas, São Paulo, v. 1, n. 1, p. 39-47, 1984.

NABHAN, G. P. Cultures of Habitat: On Culture, Nature and Story. Washington, DC: Counterpoint Press, 1987.

NOORGARD, R. Development betrayed: The end of progress and ecoevolutionary revisioning of the future. London: Routledge, 1994. 
O’DWYER, E. C. Racismo, etnicidade e políticas de identidade no Brasil: os remanescentes de quilombos na fronteira amazônica. In: HERCULANO, S.; PACHECO, T. (Org.). Racismo Ambiental. I Seminário Brasileiro contra o Racismo Ambiental. Rio de Janeiro: FASE, 2006. p. 53-72.

PARAJULI, P. Retornando ao lar Terra: etnicidades ecológicas e diversidades bioculturais na idade da ecologia. In: HERCULANO, S.; PACHECO, T. (Org.). Racismo Ambiental. I Seminário Brasileiro sobre Racismo Ambiental. Rio de Janeiro: FASE, 2006. p. 100-118.

QUIJANO, A. Modernidad, identidad y utopía en América Latina. Lima: Sociedad y Política Ediciones, 1988.

. "Raza”, “etnia”, "nación” en Mariátegui: cuestiones abiertas. In: FORGUES, R. (Org.). José Carlos Mariátegui y Europa. La outra cara del descubrimiento. Lima: Amauta, 1992.

Colonialidade do poder, eurocentrismo e América Latina. In: LANDER, E. (Org.). A Colonialidade do Saber, Eurocentrismo e Ciências Sociais. Buenos Aires: CLACSO, 2005.

QUINTAS, J. S. (Org.). Pensando e praticando a educação ambiental na gestão do meio ambiente. 2. ed. Brasília: MMA/IBAMA, 2002. (Série Educação Ambiental).

- Introdução à Gestão Ambiental Pública. Série Educação Ambiental. Brasília: MMA/IBAMA, 2005.

SANTOS, G.; SILVA, M. P. Racismo no Brasil: percepções da discriminação e do preconceito no século XXI. São Paulo: Perseu Abramo, 2005.

SARKAR, S. Restaurando o Mundo Selvagem. In: DIEGUES, A. C. (Org.). Etnoconservação: novos rumos para a Conservação da Natureza. 2. ed. São Paulo: Hucitec, 2000. p. 47-65.

SILVA, M. J. Racismo à Brasileira: raízes históricas. 3. ed. São Paulo: Anita, 1995.

SCOTTO, G.; LIMONCIC, F. (Org.). Conflitos Sócio-Ambientais no Brasil: O Caso do Rio de Janeiro. Rio de Janeiro: Projeto Meio Ambiente e Democracia, 1997. (v. 2).

THOMAS, K. O Homem e o Mundo Natural: mudanças de atitudes em relação às plantas e aos animais, 1500-1800. São Paulo: Companhia das Letras, 1988 [1983].

VIANNA, L. P. Considerações críticas sobre a construção da idéia da população tradicional no contexto das unidades de conservação. 1996. Dissertação (Mestrado) -Universidade de São Paulo, 1996.

WALLERSTEIN, I. The Modern World-System. New York: Academic Press, 1974-1989. (3 v.).

. Capitalismo histórico e Civilização capitalista. Rio de Janeiro: Contraponto, 2001. 